\title{
Modeling of Subsurface defects in CFRP composites
}

By *V.R.Manjula and ${ }^{* *}$ G.Prasad

\author{
*Bhavan's Vivekananda College, Sainikpuri, Secunderabad, Telangana \\ vrmanjula@rediffmail.com \\ **Department of Physics, Osmania University, 500078 India \\ gudurup@gmail.com
}

\begin{abstract}
Infrared Thermography can be used to detect the subsurface defects in materials. This paper presents the results of Finite difference simulations of thermographs of (CFRP) Carbon Fiber Reinforced Plastics composite materials having Teflon inserts as defects. The inserts are assumed to be parallelepiped. The three dimensional parabolic heat conduction equation is solved and the temporal and spatial variation of signal and thermal contrast for defect situated at different depths are analyzed. The detectability window of the defects in terms of the number of the harmonic in the Fourier Transform spectra (both amplitude and phase) is identified. It has been observed that the phase images give better understanding of the defects in the composites.
\end{abstract}

\section{Introduction}

Infrared thermography is widely used for the Non-destructive testing (NDT), (for the defect detection and characterization) of the multi- layered composite materials. The thermographic inspection of composite materials involves subjecting the specimen to a heat pulse for a short time and then analyzing the thermal response of the specimen under study. As the heat diffuses through the specimen, the defects contained in it causes perturbations in the heat flow which are revealed by the images of infrared camera. The acquired thermal images are processed using different signal processing techniques [1-5]. The thermal images are acquired at a maximum frame capture rate of about $50 \mathrm{~Hz}$ frequency under experimental conditions such as non uniform heating, presence of different noise sources and anisotropic characteristics of specimen under study or the factors that limit the accuracy and repeatability of the data [68].

This paper presents the results of numerical simulations of Teflon inserts in carbon fiber reinforced plastic(CFRP) composites using finite difference method. It is aimed at identifying the optimum condition for defect detection which helps in overcoming some of the difficulties of experimental studies enumerated in the above paragraph. Also, knowledge of optimum condition of defect detection would help us in avoiding the repetition of the ex-periments.

The paper is aimed at reporting the results of simulations of thermal NDT in-spection of CFRP laminate with Teflon inserts and the evaluation of the defect parameters for the sub surface defects. Modeling of the composite laminate with unidirectional fibers and the calculation of the temperature distributions in anisotropic composites done by implement-ing the finite difference method. A comparison of the numerical simulations with experimental images is made.

\section{Algorithm:}

The mathematical description of the problem is given by the fo llowing heat conduction equation in three dimensions.

$\frac{\partial T(x, y, z, \tau)}{\partial \tau}=\alpha_{i}^{x} \frac{\partial^{2} T_{i(x, y, z, \tau)}}{\partial x^{2}}+\alpha_{i}^{y} \frac{\partial^{2} T_{i(x, y, z, \tau)}}{\partial y^{2}}+\alpha_{i}^{Z} \frac{\partial^{2} T_{i(x, y, z, \tau)}}{\partial z^{2}}$ 
where $\mathbf{i}=1$ to15 (six layers and nine defects as in fig 1) and $\alpha_{i}^{q}(\mathrm{q}=\mathrm{x}, \mathrm{y}, \mathrm{z})$ are the components of thermal diffusivity.

The initial condition is as

$T_{i}(\mathrm{~T}=0)=T_{\text {in }}$

$T_{i}$ is the temperature in the $\mathrm{i}^{\text {th }}$ region

$T_{\text {in }}$ is the initial specimen temperature.

The boundary condition on front surface which is subjected to both heating and cooling is

$-k^{z} \cdot \frac{\partial T(x, y, z=0, \tau)}{\partial z}=\mathrm{Q}(\mathrm{x}, \mathrm{y}, \mathrm{T})-h_{f} \cdot\left[T_{i}(\mathrm{x}, \mathrm{y}, \mathrm{z}, \mathrm{T})-T_{a m b}\right]$

$\frac{\partial T(x, y, \tau)}{\partial x}=0 ; \quad \frac{\partial T(x, y, \tau)}{\partial y}=0$

$T_{i}(\mathrm{x}, \mathrm{y}, \mathrm{z}, \mathrm{T})=T_{i+1}(\mathrm{x}, \mathrm{y}, \mathrm{z}, \mathrm{T})$ and $\quad k_{i}^{q_{j}} \frac{\partial T_{i}(x, y, z, \tau)}{\partial q_{j}}=k_{i+1}^{g_{j}} \frac{\partial T_{i}(x, y, z, \tau)}{\partial q_{j}}$

Eqs (4) are the boundary conditions on side surfaces along $x$ and $y$ and Eqs (5) are the heat flux and temperature continuity conditions on the boundaries between the layers and between the layers and the defects.

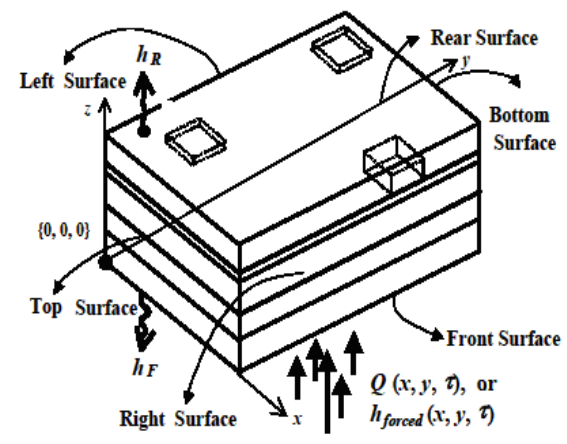

Fig 1. 3d model of a six layer specimen with sub surface defects

A finite difference approach is applied in solving the heat conduction problem and is at-tempted to model a laminate consisting of 30 layers that may contain up to nine defects [9]. The sample is heated on the front surface with an external Gaussian heating pulse.

$Q=Q_{m} \cdot \exp \left[-\sigma \cdot\left(x-x_{o}^{2}+y-y_{o}^{2}\right)\right]$

where $Q_{m}$ is the max. heat flux and $\left(\mathrm{x}_{0}, \mathrm{y}_{0}\right)$ is the position of the heat source. The absorbed heat power is related to incident power density by the following eq.

$\mathrm{Q}(\mathrm{x}, \mathrm{y}, \mathrm{z}, \tau)=Q_{m}(x, y, \tau) \cdot \varepsilon(\mathrm{x}, \mathrm{y})$ where $\varepsilon(\mathrm{x}, \mathrm{y})$ specifies the surface emissivity.

The heat flux centre may be placed at an arbitrary point on the front surface. As the external stimulus is applied, the temperature of the material changes rapidly because of the thermal wave front propagation by diffusion process and also by radiation and convection losses. The heat exchange coefficients, $h$ are determined at each time step, using the following expressions from heat conduction theory depicting Stefan's law of radiation.
$h_{F}^{r a d}(\tau)=\frac{\sigma\left[\mathcal{E}_{F} T_{F}^{4}(\tau)-\mathcal{E}_{a m b} T_{a m b}^{4}\right]}{T_{F}(\tau)-T_{a m b}}$
$h_{R}^{r a d}(\tau)=\frac{\sigma\left[\mathcal{E}_{R} T_{R}^{4}(\tau)-\mathcal{E}_{\text {amb }} T_{a m b}^{4}\right]}{T_{R}(\tau)-T_{\text {amb }}}$
$h_{F}^{c o n v}(\tau)=1.7\left[T_{F}(\tau)-T_{a m b}\right]^{1 / 3}$
$h_{R}^{\text {conv }}(\tau)=1.7\left[T_{R}(\tau)-T_{\text {amb }}\right]^{1 / 3}$ 
Where $h_{F}=h_{F}^{\text {conv }}+h_{F}^{\text {rad }} ; \quad h_{R}=h_{R}^{\text {conv }}+h_{R}^{\text {rad }}$

Here, the Stephan-Boltzmann constant $\sigma=5.67 \times 10^{-8} \mathrm{~W} / \mathrm{m}^{2} / \mathrm{K}^{4} .{ }^{\varepsilon_{\mathrm{FR}}}$

specimen surface and $\quad \varepsilon_{a m b} \quad$ is the emissivity of the ambient. is the emissivity of the

The eqs (8) show that both the heat exchange coefficients $h_{F}$ and $h_{R}$ depend on temperature difference between the specimen and ambient temperature. Thermal properties of the sample and the defects can be defined independently along all the three axes so that even an anisotropic laminate can be characterized. In modeling the anisotropic solids, only the thermal conductivity is considered to be anisotropic where as the specific heat capacity and density are taken as constants [3,9]. The sample side surfaces are taken as adiabatic where as in between the layers and between the defects and layers, the temperature and the heat flux continuity conditions are assumed. Unlike in other NDT models, the thermal capacitive defects rather than the thermal resistive defects are taken into account which means both thermal diffusivity and conductivity are considered. This makes it possible to give a precise description of the physical phenomena occurring in defects.

The rate of diffusion of heat through the specimen is reduced by the presence of defects in it and hence when the surface temperature is captured, it is observed that the temperatures of the regions containing subsurface defects are different from that of the sur-rounding defect free regions [5]. The difference temperature signal $\Delta T$ defined below is obtained for various defects by the surface inspection of the specimen.

$$
\Delta T(i, j, \tau)=T(i, j)-T\left(m_{\text {ref }}, n_{\text {ref }}, \tau\right)
$$

A thermal contrast is produced in the specimen characterizing the defect and the composite used. The detectability of the subsurface defects in the infrared image also de-pends on the running contrast $\mathrm{C}(\mathrm{t})$ between the defect and the non defect region.

$$
C_{1}(t)=\frac{T_{\text {def }}{ }^{(t)}-T_{\text {non-def }}\left(t_{0}\right)}{T_{\text {non-def }}(t)-T_{\text {non-def }}\left(t_{0}\right)}
$$

Where T stands for temperature signal. However during simulations, another definition of running contrast given by equation (11) is used [9].

$$
C_{2}(t)=\frac{T_{\text {def }}-T_{\text {non-def }}}{T_{\text {non-def }}-T_{\text {non-def }}} \equiv \frac{\Delta T}{T_{\text {non-def }}} \equiv 1-C_{1}{ }^{(t)}
$$

The maximum difference temperature signal and the running contrast are com-puted for defects,thus simulating the model of the sample. ThermoCalc ${ }^{\mathrm{TM}}-30 \mathrm{~L}$ allows us to evaluate the following parameters:

$\Delta T_{m}^{F} \quad{ }^{0} \mathrm{C}$ - Maximum difference temperature signal over a defect on front surface $\mathrm{F}$,

$\tau_{m}^{F}(\Delta T) s \quad-\quad$ The time when $\Delta T_{m}^{F}$ occurs

$C_{m}^{F}$ - Maximum running temperature contrast on Front -surface

$\tau_{m}^{F}\left(\quad-\right.$ The time when $\quad C_{m}^{F}$ occurs

\subsection{Modeling}

In an attempt to arrive at an optimum condition for defect detection, Ther-moCalc ${ }^{\mathrm{TM}}{ }_{-} \mathbf{3 0 L}$ is used for the modeling of the sample under consideration. The software is based on the numerical solution to the 3D transient heat conduction problem for a specimen, which is a thirty layered parallelepiped shaped solid body placed in a system of Cartesian co-ordinates.

Theoretical estimates of conditions pertaining to best detectability of defects is done by inspecting a flat CFRP laminate of $4 \mathrm{~mm}$ thickness and of size 25X35mm. The sample consists of four layers of CFRP of $1 \mathrm{~mm}$ thickness with three Teflon inserts of $5 \mathrm{~mm}$ size, inserted at depths $1.252 .25 \mathrm{~mm}$ and $3.5 \mathrm{~mm}$. The fourth defect of size $2.5 \mathrm{~mm}$ is inserted at a same depth as defect1. A unidimensional CFRP material is used for this purpose. All the de-fects are simulated as parallelepipeds which may lie deep inside the layers or at the point of contact of layer surfaces but can never cross the layer boundaries. The 
temperature signal caused by the defect at any point in the sample must not exceed the degradation temperature of the sample. $T_{\max }<T_{\text {deg }}$ where $T_{\text {deg }}=120^{\circ} \mathrm{C}$. The differential temperature signal $\Delta_{T}$ must be higher than the temperature

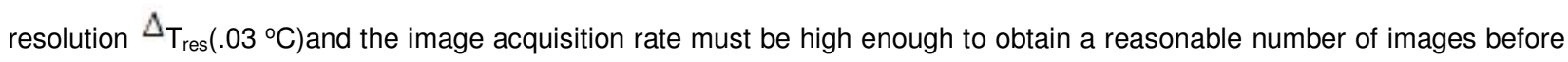
an optimum observation is reached [4]. The above conditions are essential for the comparison of theoretical and experimental results

\subsubsection{Specimen dimensions}

Specimen type: Carbon fiber reinforced plastic composite of dimensions

Length $=0.025 \mathrm{~m} ;$ Width $=0.035 \mathrm{~m}$ and Thickness $=0.001 \mathrm{~m}$ and CFRP material has anisotropic properties; therefore conductivity of specimen varies with the direction

\subsubsection{Specimen properties [4]:}

$1^{\text {st }}$ component of conductivity tensor in $\mathrm{XY}$-plane $(\mathrm{W} / \mathrm{m} . \mathrm{K})=2.33$

$2^{\text {nd }}$ component of conductivity tensor in $\mathrm{XY}$-plane $(\mathrm{W} / \mathrm{m} . \mathrm{K})=0.53$

Conductivity in direction $\mathrm{Z}(\mathrm{W} / \mathrm{m} . \mathrm{K})=0.53$

Heat capacity $(\mathrm{J} / \mathrm{kg} \cdot \mathrm{K})=846$; Density $\left(\mathrm{kg} / \mathrm{m}^{3}\right)=1500$

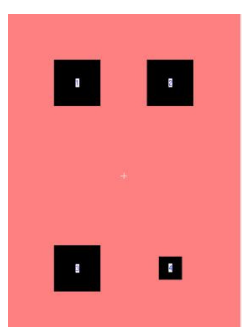

Fig 2. Location of Teflon insert in the sample.

\subsubsection{Dimensions of Teflon inserts}

(For defects 1, 2 and 3.)

Defect length (along x-axis):

Defect width (along y-axis):

Defect thickness (along z-axis):
(For defect 4)

$$
\begin{array}{lll}
0.005 \mathrm{~m} & \text { Defect length (along x-axis): } & 0.0025 \mathrm{~m} \\
0.005 \mathrm{~m} & \text { Defect width (along y-axis): } & 0.0025 \mathrm{~m} \\
0.0004 \mathrm{~m} & \text { Defect thickness (along z-axis): } & 0.0004 \mathrm{~m}
\end{array}
$$

Defect initial points are varied along $x$ and $y$ axes depending on the position at which it is placed on the chosen layer and is varied along z-axis based on the depth at which defect is placed in the laminate.

\subsubsection{Defects Properties:}

Here defect Teflon is taken to be isotropic, sothe properties of Teflon are same in all directions.

$1^{\text {st }}$ component of conductivity tensor in $\mathrm{XY}$-plane $(\mathrm{W} / \mathrm{m} . \mathrm{K})=0.23$

$2^{\text {nd }}$ component of conductivity tensor in XY-plane $(\mathrm{W} / \mathrm{m} . \mathrm{K})=0.23$

Conductivity in direction $Z(\mathrm{~W} / \mathrm{m} . \mathrm{K})=0.23$

Heat capacity $(\mathrm{J} / \mathrm{kg} . \mathrm{K})=1.046$ Density $\left(\mathrm{kg} / \mathrm{m}^{3}\right)=2100$ 
The sample model was heated on the front surface with a square heat pulse. The input heat flux may be restricted to a max. of $15 \mathrm{kw} / \mathrm{m}^{2}$ so that the sample was heated up to a maximum of $90^{\circ} \mathrm{C}$ which is less than the degradation temperature of the material. The input heat flux and heating times are varied and along with the material properties. By simulating the defects at different depths, signal and running contrasts were obtained varying heat input flux and heating times each time. The following tables list out the calculated data. Bold values indicate the experimentally detectable signal values.

Table 1 : Maximum Signal $\Delta T$ values for defect1 at depth $1.5 \mathrm{~mm}$ for various heat flux and heating times

\begin{tabular}{|c|l|l|l|l|l|l|l|l|}
\hline $\begin{array}{c}\text { Heating } \\
\text { time }(\mathrm{sec})\end{array}$ & $\begin{array}{l}\text { HS:1000 } \\
\left(\mathrm{w} / \mathrm{m}^{2}\right)\end{array}$ & $\begin{array}{l}\text { HS:2000 } \\
\left(\mathrm{w} / \mathrm{m}^{2}\right)\end{array}$ & $\begin{array}{l}\text { HS:4000 } \\
\left(\mathrm{w} / \mathrm{m}^{2}\right)\end{array}$ & $\begin{array}{l}\text { HS:6000 } \\
\left(\mathrm{w} / \mathrm{m}^{2}\right)\end{array}$ & $\begin{array}{l}\text { HS:8000 } \\
\left(\mathrm{w} / \mathrm{m}^{2}\right)\end{array}$ & $\begin{array}{l}\text { HS:10000 } \\
\left(\mathrm{w} / \mathrm{m}^{2}\right)\end{array}$ & $\begin{array}{l}\text { HS:12000 } \\
\left(\mathrm{w} / \mathrm{m}^{2}\right)\end{array}$ & $\begin{array}{l}\text { HS:15000 } \\
\left(\mathrm{w} / \mathrm{m}^{2}\right)\end{array}$ \\
\hline 5 & 0.1087 & 0.2175 & 0.4349 & 0.6524 & 0.8699 & 1.081 & 1.305 & 1.631 \\
\hline 10 & 0.1588 & 0.3177 & 0.6364 & 0.9531 & 1.271 & 1.588 & 1.906 & 2.383 \\
\hline 15 & 0.1791 & 0.3582 & 0.7164 & 1.075 & 1.433 & 1.791 & 2.149 & 2.687 \\
\hline 20 & 0.1877 & 0.3754 & 0.7508 & 1.126 & 1.502 & 1.877 & 2.252 & 2.85 \\
\hline 25 & 0.1916 & 0.3832 & 0.7664 & 1.15 & 1.533 & 1.916 & 2.299 & 2.874 \\
\hline 30 & 0.193 & 0.3861 & 0.7722 & 1.158 & 1.544 & 1.93 & 2.317 & 2.896 \\
\hline
\end{tabular}


http://dx.doi.org/10.21611/qirt.2015.0073

Table 2 : Maximum Signal $\Delta T$ values for defect2 at depth $2.25 \mathrm{~mm}$ for various heat flux and heating times

\begin{tabular}{|c|c|c|c|c|c|c|c|c|}
\hline Heating & HS:1000 & HS:2000 & HS:4000 & HS:6000 & HS:8000 & HS:10000 & HS:12000 & HS:15000 \\
time(sec) & $\left(\mathrm{w} / \mathrm{m}^{2}\right)$ & $\left(\mathrm{w} / \mathrm{m}^{2}\right)$ & $\left(\mathrm{w} / \mathrm{m}^{2}\right)$ & $\left(\mathrm{w} / \mathrm{m}^{2}\right)$ & $\left(\mathrm{w} / \mathrm{m}^{2}\right)$ & $\left(\mathrm{w} / \mathrm{m}^{2}\right)$ & $\left(\mathrm{w} / \mathrm{m}^{2}\right)$ & $\left(\mathrm{w} / \mathrm{m}^{2}\right)$ \\
\hline 5 & 0.0314 & 0.06279 & 0.1256 & 0.1884 & 0.2512 & 0.314 & 0.3767 & 0.4709 \\
\hline 10 & 0.05275 & 0.1055 & 0.211 & 0.3165 & 0.422 & 0.5275 & 0.6331 & 0.7913 \\
\hline 15 & 0.06453 & 0.1291 & 0.2581 & 0.3872 & 0.5163 & 0.6453 & 0.7744 & 0.968 \\
\hline 20 & 0.07068 & 0.1414 & 0.2827 & 0.4241 & 0.5655 & 0.7069 & 0.8482 & 1.06 \\
\hline 25 & 0.07393 & 0.1479 & 0.2957 & 0.4436 & 0.5915 & 0.7394 & 0.8872 & 1.109 \\
\hline 30 & 0.06499 & 0.13 & 0.26 & 0.39 & 0.52 & 0.6499 & 0.7799 & 0.9749 \\
\hline
\end{tabular}

Table 3 : Maximum Signal $\Delta T$ values for defect3 at depth $3.5 \mathrm{~mm}$ for various heat flux and heating times

\begin{tabular}{|c|c|c|c|c|c|c|c|c|}
\hline $\begin{array}{c}\text { Heating } \\
\text { time }(\mathrm{sec})\end{array}$ & $\begin{array}{c}\text { HS:1000 } \\
\left(\mathrm{w} / \mathrm{m}^{2}\right)\end{array}$ & $\begin{array}{c}\text { HS:2000 } \\
\left(\mathrm{w} / \mathrm{m}^{2}\right)\end{array}$ & $\begin{array}{c}\text { HS:4000 } \\
\left(\mathrm{w} / \mathrm{m}^{2}\right)\end{array}$ & $\begin{array}{c}\text { HS:6000 } \\
\left(\mathrm{w} / \mathrm{m}^{2}\right)\end{array}$ & $\begin{array}{c}\text { HS:8000 } \\
\left(\mathrm{w} / \mathrm{m}^{2}\right)\end{array}$ & $\begin{array}{c}\text { HS:10000 } \\
\left(\mathrm{w} / \mathrm{m}^{2}\right)\end{array}$ & $\begin{array}{c}\text { HS:12000 } \\
\left(\mathrm{w} / \mathrm{m}^{2}\right)\end{array}$ & $\begin{array}{c}\text { HS:15000 } \\
\left(\mathrm{w} / \mathrm{m}^{2}\right)\end{array}$ \\
\hline 5 & 0.0314 & 0.06279 & 0.1256 & 0.1884 & 0.2512 & 0.314 & 0.3767 & 0.4709 \\
\hline 10 & 0.05275 & 0.1055 & 0.211 & 0.3165 & 0.422 & 0.5275 & 0.6331 & 0.7913 \\
\hline 15 & 0.06453 & 0.1291 & 0.2581 & 0.3872 & 0.5163 & 0.6453 & 0.7744 & 0.968 \\
\hline 20 & 0.07068 & 0.1414 & 0.2827 & 0.4241 & 0.5655 & 0.7069 & 0.8482 & 1.06 \\
\hline 25 & 0.07393 & 0.1479 & 0.2957 & 0.4436 & 0.5915 & 0.7394 & 0.8872 & 1.109 \\
\hline 30 & 0.06499 & 0.13 & 0.26 & 0.39 & 0.52 & 0.6499 & 0.7799 & 0.9749 \\
\hline
\end{tabular}


http://dx.doi.org/10.21611/qirt.2015.0073

Table 4: Maximum Signal $\Delta T$ values for defect 4at depth 1.5mmand a reduced size of $2.5 \times 2.5 \mathrm{~mm}$ for various heat flux and heating times

\begin{tabular}{|c|l|l|l|l|l|l|l|l|}
\hline Heating & HS:1000 & HS:2000 & HS:4000 & HS:6000 & HS:8000 & HS:10000 & HS:12000 & HS:15000 \\
time(sec) & $\left(\mathrm{w} / \mathrm{m}^{2}\right)$ & $\left(\mathrm{w} / \mathrm{m}^{2}\right)$ & $\left(\mathrm{w} / \mathrm{m}^{2}\right)$ & $\left(\mathrm{w} / \mathrm{m}^{2}\right)$ & $\left(\mathrm{w} / \mathrm{m}^{2}\right)$ & $\left(\mathrm{w} / \mathrm{m}^{2}\right)$ & $\left(\mathrm{w} / \mathrm{m}^{2}\right)$ & $\left(\mathrm{w} / \mathrm{m}^{2}\right)$ \\
\hline 5 & 0.0314 & 0.06279 & 0.1256 & 0.1884 & 0.2512 & 0.314 & 0.3767 & 0.4709 \\
\hline 10 & 0.05275 & 0.1055 & 0.211 & 0.3165 & 0.422 & 0.5275 & 0.6331 & 0.7913 \\
\hline 15 & 0.06453 & 0.1291 & 0.2581 & 0.3872 & 0.5163 & 0.6453 & 0.7744 & 0.968 \\
\hline 20 & 0.07068 & 0.1414 & 0.2827 & 0.4241 & 0.5655 & 0.7069 & 0.8482 & 1.06 \\
\hline 25 & 0.07393 & 0.1479 & 0.2957 & 0.4436 & 0.5915 & 0.7394 & 0.8872 & 1.109 \\
\hline 30 & 0.06499 & 0.13 & 0.26 & 0.39 & 0.52 & 0.6499 & 0.7799 & 0.9749 \\
\hline
\end{tabular}

\subsection{Discussion:}

In case of defect 1, the maximum temperature signal increased with increase in heating time and reached a maximum. Signal in the case of Defect 2, tends to increase gradually to attain a peak value and then again found to decrease. The signal gradually increases in defect 3 , at a depth of $3.5 \mathrm{~mm}$ whereas in defect 4 at a depth $1.5 \mathrm{~mm}$ and with a reduced size of $2.5 \mathrm{~mm}$, the signal increases sharply till a heating time of $10 \mathrm{sec}$ is reached and then gradually increases to reach a saturation end.

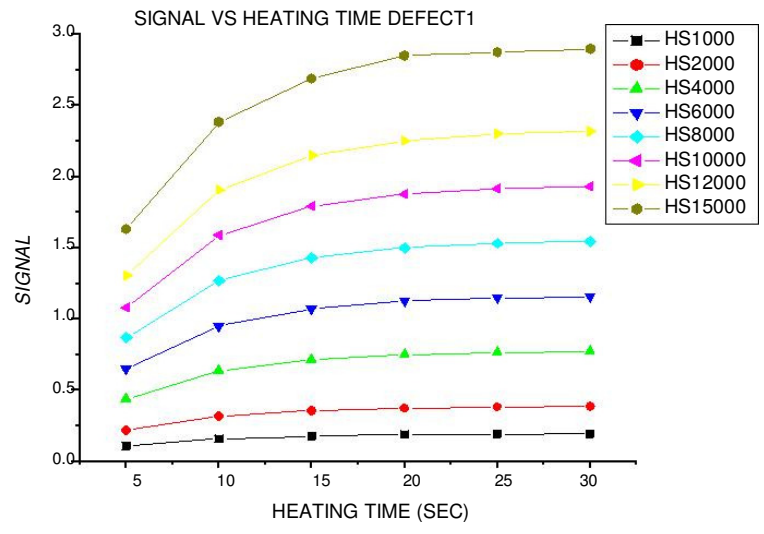

Fig 3. Variation of signal in defect1

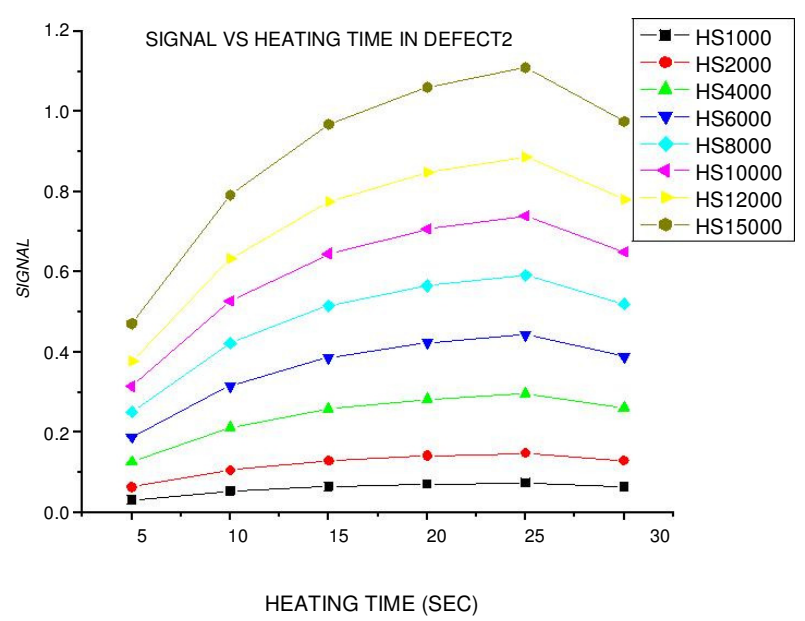

Fig 4. Variation of signal in defect 2 
http://dx.doi.org/10.21611/qirt.2015.0073
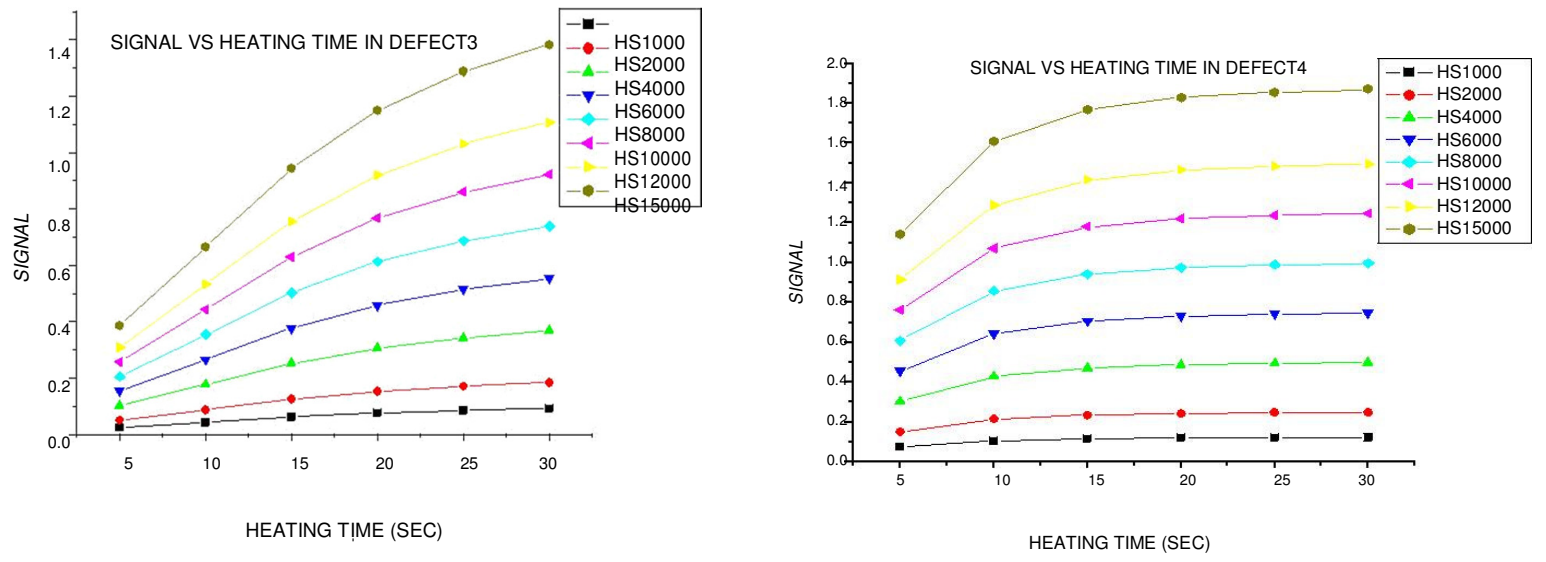
Fig 5. Variation of signal in defect 3

Fig 6. Variation of signal in defect 4

The running temperature contrast reaches a peak at very low heating times and reaches mini-mum value towards the higher heating times. The variation in running contrast gets flattened at a heating time of $20 \mathrm{~s}$ in all the three defects except defect 2, indicating an optimum condi-tion for defect detection is at heating time of 20s in these composites.

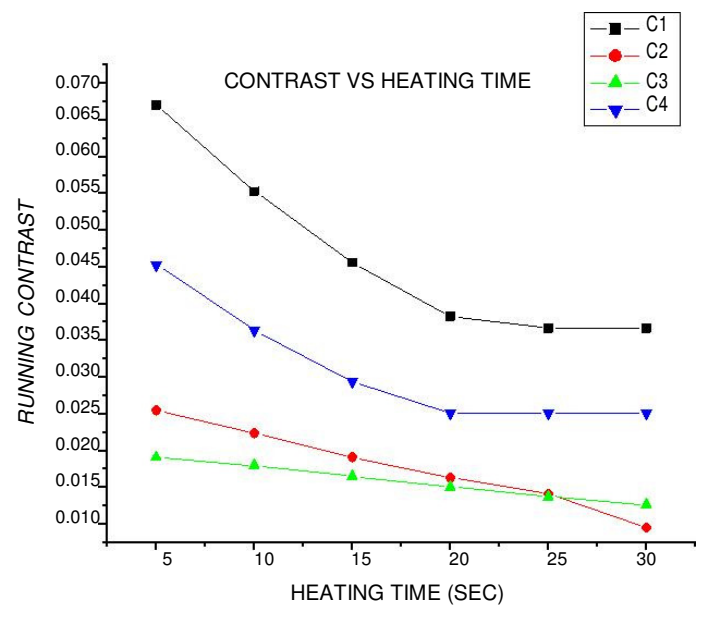

Fig 7. Running contrast variation with heating time

The Peak value observed in the signal for defect 2 at $25 \mathrm{sec}$ is found to be significant in find-ing the optimum condition as the phase image of the detect also gives an indication of the second defect which is deeper, only at a heating time of $25 \mathrm{sec}$.( Here it may be mentioned that phase image gives the first test for detecting the defect) As it is, another parameter for "best detectability" window, the input heat flux is constrained by the condition that the surface temperature should not exceed the upper limit of $120^{\circ} \mathrm{C}$. Simulation results shows that at heat flux of $15 \mathrm{KW} / \mathrm{m}^{2}$ and above, the surface temperature above this defect is tending to be high enough $\left(>90^{\circ} \mathrm{C}\right)$ which may cause degradation in the material with little increase in the heat input. Thus the heat flux may be chosen to be $12 \mathrm{KW} / \mathrm{m}^{2}$ for subsequent simulations in the present study.

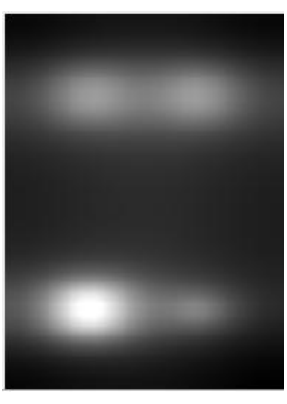

Fig 8.

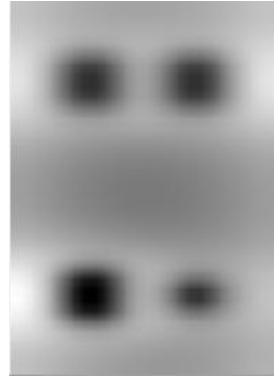

Fig 9

Fig 8. Fourier transform magnitude image when all the defects are at same depth of $1.5 \mathrm{~mm}$.

Fig 9. Fourier transform phase images with defects at same depth. 
The thermographic Fourier transform phase images of defects when they are placed at same depth and at different depths, with defect 3 being deeper, clearly shows that the deeper the defect, the possibility of detecting the defect becomes difficult. Defect 1 and defect 4 which are at a depth of $1.5 \mathrm{~mm}$, placed in the second layer of the laminate are able to be detected right through the experiment, at a very low heat input of $1000 \mathrm{~W} / \mathrm{m}^{2}$ and a heating time of $10 \mathrm{sec}$.Attempting to obtain the optimum condition for detecting defect 2 and 3 , placed in the third and the fourth layer of the laminate, at a depth of $2.25 \mathrm{~mm}$ and $3.5 \mathrm{~mm}$ re-spectively, simulations were carried out for the optimization of the parameters with regards to heat flux and heating time. Here as different defects show different variations in the signal (with defects $1 \& 4$ being similar), the variations observed in the running contrast is considered for optimization. The following table (Table5) gives the optimum detection parameters for defect 2 and defect 3.

Table 5: Optimization of detectable parameters of defect 2 and defect 3

\begin{tabular}{|c|c|c|c|c|}
\hline Defect No\# & Heat flux & Heating time & Observation time & Harmonic \\
& $\left(\mathrm{W} / \mathrm{m}^{2}\right)$ & $(\mathrm{sec})$ & 30 & 6th \\
\hline Defect 2 & 12000 & 25 & 30 & 4 th \\
\hline
\end{tabular}

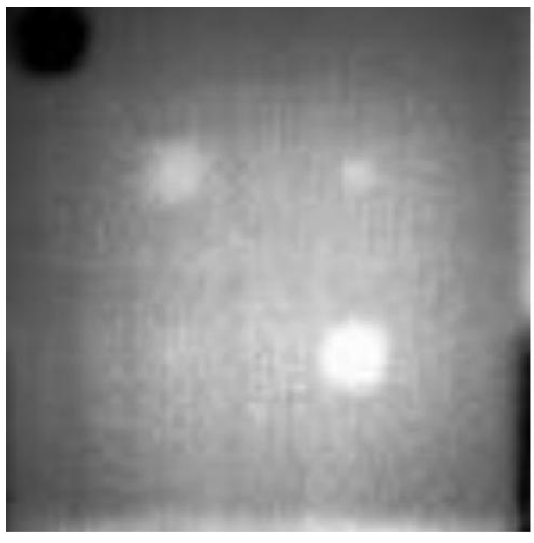

(a)

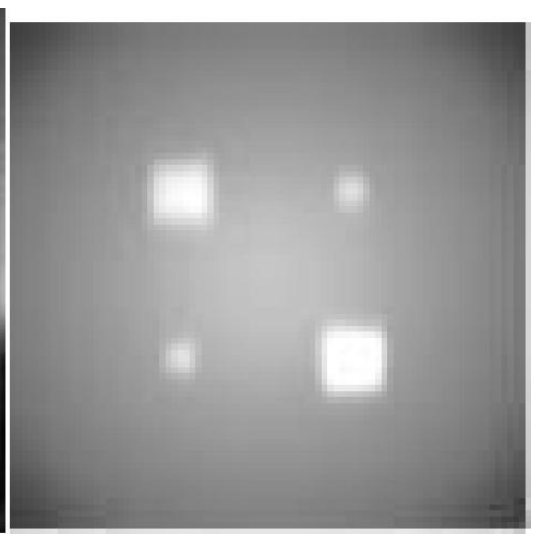

(b)

Fig 10. Thermal NDT of a 15- mm thick graphite/epoxy sample (10s heating):

(a)-raw image at the optimum observation time (Front surface),

(b)-same as a), simulation result (ThermoCalc - 6L program) (after reference[12])

Some experimental results and data processing are presented in Fig. 10 for a $15 \mathrm{~mm}$ - thick graphite/epoxy sample with Teflon inserts [12]. Obviously, because of the large sample thickness, the $F$-surface test has proven to provide better defect "visibility" than the $R$-surface test. The Fourier transformation applied to the time evolution of pixel-based temperature functions $\mathrm{T}(\mathrm{x}, \mathrm{y}, \mathrm{t})$ has been chosen as a primary processing technique intended for making decision on whether further processing has to be applied to experimental results. By computer modeling, it was immediately revealed that relatively big temperature signals which appeared over defects cannot be explained by the presence of Teflon inserts which should be in ideal thermal contact with a host composite. 


\section{http://dx.doi.org/10.21611/qirt.2015.0073}

The four defects analyzed have the following dimensions:

$$
\begin{aligned}
& \text { Defect1 diameter } 40 \mathrm{~mm} \text {; Defect depth } 1.5 \mathrm{~mm} \\
& \text { Defect2 diameter } 20 \mathrm{~mm} \text {; Defect depth } 3 \mathrm{~mm} \\
& \text { Defect3 diameter } 40 \mathrm{~mm} \text {; Defect depth } 3 \mathrm{~mm} \\
& \text { Defect4 diameter } 20 \mathrm{~mm} \text {;Defect depth } 1.5 \mathrm{~mm}
\end{aligned}
$$

The results obtained in the present simulations are similar to the reported re-sults. The calculation results observed at the above mentioned conditions are presented in the Table 6 .

Table 6: Optimum defect detectivitiy conditions for(For $Q=12000 \mathrm{~W} / \mathrm{m}^{2}, \mathrm{th}=20 \mathrm{~s}$ )

\begin{tabular}{|c|c|c|c|c|c|}
\hline Defect & Depth mm & $\Delta T_{m}^{F}$ & $\tau_{m}^{F}(\Delta T) s$ & $C_{m}^{F}$ & $\tau_{m(c)}^{F}$ \\
\hline D1 & 1.25 & 2.252 & 20 & 0.03829 & 21.6 \\
\hline D2 & 2.25 & 0.8482 & 22.7 & 0.01631 & 23.6 \\
\hline D3 & 3.5 & 0.9194 & 20 & 0.01508 & 25.2 \\
\hline D4 & 1.5 & 1.464 & 20 & 0.02518 & 8.8 \\
\hline
\end{tabular}

\section{Conclusions}

It is concluded that best detectability is observed for $12 \mathrm{KW} / \mathrm{m}^{2}$ heat flux, heat-ing time of $20 \mathrm{~s}$ and observation time of $30 \mathrm{~s}$. The defect size, geometry and depth are impor-tant parameters to decide defect detectability window along with the thermal parameters of the materials under considerations Fourier transform magnitude and phase images of specific harmonic give interesting information about the defects. To avoid the repetition of performing the experiments in arriving at a best combination of parameters for defect detectability, a theoretical estimate of the optimum condition is of considerable use. Thermal Non Destructive Testing experiments are multi-parametric and their optimization requires careful consideration of the involved parameters. The results presented in the paper are related to a particular type of materials (composites) for which simulation is done at about times $5-20 \mathrm{sec}$. Consideration of noise (surface clutter) may influence some paper recommendations, in particular, in regards to detected size and depth.

\section{References}

[1] Xavier Maldague, Applications of Infrared thermography in Nondestructive Evaluation( University Laval, Quebeque city, Canada)

[2] X.P.V. Maldague, Theory and Practice of Infrared Technology for Non destructive Testing (Wiley, New York 2001)

[3] Vavilov V.P., Three dimensional analysis of thermal NDT problems by data simulations and processing, Thermosense XXII, SPIE, 4020,152, 2000.

[4]. K. Srinivas, A.O. Siddiqui, J. Lahiri., Thermographic Inspection of composite materials,, Proc Annual Conference ISNT NDE, 2005 
[5] X.P.V. Maldague., “ Introduction to NDT by Active Infrared thermography”, Materials Evaluation, September,1060-1073, 2002.

[6] D. J. Roth, J. R. Bodis C Bishop, Thermographic imaging for high temperature composite materials - A defect detection studyRes. Nondestr. Eval. $\underline{\mathbf{9}} 147$ (1997).

[7] I.N. Ishchuk, The detection of defects in materials using thermography measure-ment techniques $\underline{\mathbf{5 1}} \mathbf{4} 1$ (2008).

[8] Harry I Ringermache r, Bryon Knight, Tian Li, Yuri A Plotnikov, Gulperi Aksel, Donald R Howard, Jeffer L Thompson Non-destructive testing and evaluation 2293 (2007)

[9] ThermoCalc ${ }^{\mathrm{TM}}-\mathbf{3 0 L}$, Operational manual, version 1.0, 2008

[10] Maddague X.and Marinetti. S, "Pulse Phase Infrared Thermography" J. Applied Phys., 79,2694,1996.

[11] Plotnikov Y.A. and Winfree W.P., Temporal treatment of thermal response for Defect depth estimation. In proceedings of review of progress in quantitave Non

Destructive Evaluation. 19A, AIP conference Procedings 509 Montreal Canada edited By D.O.Thompson and D.E. Chimenti. Pp. 587-594, 1999.

[12] V.Vavilov, Determining limits of Thermal NDT of thick graphite/epoxy composites ECNDT, 2006 